\title{
Abstracts: French and German
}

\section{Unilever et l'Allemagne dans les années I930: entreprise multinationale, responsabilité de la firme et dictature nazie}

Pour les historiens, la raison pour laquelle une véritable compréhension de la signification de la dictature d'Hitler n'a pas émergé au sein des démocraties de l'entre-deux-guerres reste durablement une question d'un grand intérêt. Cet article analyse comment Unilever a répondu au défi du risque politique posé par le Troisième Reich. Il examine comment des aspects de son activité économique suscitant des questions morales ont pesé contre la nécessité de survivre commercialement. C'est seulement tardivement qu'on a réalisé qu'Unilever pouvait être vue comme une complice involontaire dans les activités criminelles de la dictature. Tandis que la culture de la firme reflétait les valeurs de la société contemporaine, le commerce multinational était en partie responsable de ne pas avoir donné l'alarme sur les grands dangers inhérents au national socialisme.

\section{Multinationale Unternehmen, 'Corporate Responsibility' und die Nazidiktatur: der Fall Unilever und Deutschland in den I930er Jahren}

Weshalb die Demokratien der Vorkriegszeit kein umfassenderes Verständnis von der Bedeutung der Hitler-Diktatur entwickelten, bleibt eine Frage von historischem Interesse. Dieser Aufsatz analysiert, wie Unilever auf die politischen Risiken infolge des Dritten Reichs reagierte, und wie Aspekte des Geschäftslebens, die zu moralischen Fragen wurden, gegen die Notwendigkeit des kommerziellen Überlebens abgewogen wurden. Die Erkenntnis, dass Unilever möglicherweise als unbewusster Mittäter der kriminellen Handlungen der Diktatur gesehen werden könnte, scheint dem Unternehmen erst spät in den Sinn gekommen zu sein. Während die Unternehmenskultur die Werte der damaligen Gesellschaft widerspiegelte, waren multinationale Unternehmen mit dafür verantwortlich, nicht auf die dem Nationalsozialismus immanenten speziellen Gefahren aufmerksam gemacht zu haben.

\section{Guerre, mobilisation industrielle et société en Irlande du nord, I939-1945}

Dans la nouvelle historiographie économique, politique et sociale de la seconde guerre mondiale, les études régionales fondées sur des archives peuvent apporter une large contribution. Cet article examine le processus de mobilisation industrielle en Irlande du nord, une région politiquement divisée dans l'Europe du nord avec son propre gouvernement à Belfast mais aussi partie intégrante de la Grande Bretagne. On analyse l'évolution du cadre administratif de la production de guerre, le débat sur la conscription militaire et industrielle, le rôle des femmes et les conséquences économiques de l'éloignement par rapport à Londres. Cet article ajoute ainsi de nouvelles connaissances à celles, limitées, sur la mobilisation régionale, et contribue à l'histoire de l'Irlande du nord. 


\section{Krieg, industrielle Mobilisierung und Gesellschaft in Nordirland, I939-I945}

Auf Archivmaterial basierende Regionalstudien können viel Neues zur ökonomischen, politischen und sozialen Geschichte des Zweiten Weltkrieges beisteuern. Dieser Aufsatz betrachtet den Prozess der industriellen Mobilisierung in Nordirland, einer politisch geteilten Region im Nordwesten Europas, die Teil Grossbritanniens war, aber eine eigene Regierung in Belfast hatte. Es werden der sich verändernde administrative Rahmen der Kriegsproduktion, die Debatte über militärische und industrielle Wehr- und Arbeitspflicht, die Rolle der Frauen und die wirtschaftlichen Auswirkungen aufgrund der geographischen Entfernung von London untersucht. Der Artikel ergänzt unser begrenztes Wissen über regionale Mobilisierung und beleuchtet einen vernachlässigten Aspekt der Geschichte Nordirlands.

\section{Vladko Maček et la droite politique croate, I928-I94I}

On peut affirmer de façon argumentée que le Parti paysan croate était le plus important parti politique de Croatie durant l'existence de la première Yougoslavie (I9I 8-4I). Durant la direction de Vladko Maček (I 879-I964), ce parti entra dans la période la plus difficile de son histoire: il devait faire face à la dictature royale (I929-34) du roi Aleksandar Karadjordjević; la grande dépression économique; et un climat politique extrêmement volatil dans lequel les extrêmes à droite et à gauche, représentés en Croatie par le mouvement Ustasa et par les partis communistes, faisaient face au pouvoir. Cet article examine les relations conflictuelles entre le Parti paysan de Maček et le mouvement fasciste Ustasa entre I929 et I94I, et analyse la place et l'héritage de Maček dans l'histoire politique du XXe siècle de la Croatie.

\section{Vladko Maček und die kroatische politische Rechte, I928-I94I}

Die Kroatische Bauernpartei war wohl die wichtigste politische Partei Kroatiens im ersten jugoslawischen Staat (I9I8-4I). Unter der Führung Vladko Mačeks (I879-I964) erlebte sie die schwierigste Periode ihrer Geschichte: sie war gezwungen, sich mit der diktatorischen Monarchie (1929-34) von König Aleksandar Karadjordjević, der grossen Depression, wachsenden nationalen Spannungen und einem zunehmend unbeständigen politischen Klima auseinanderzusetzen. Dabei kämpften die extremen Linken und Rechten, in Kroatien durch die Ustaša und kommunistische Parteien repräsentiert, um die Macht. Der Artikel untersucht die schwierige Beziehung zwischen Mačeks Kroatischer Bauernpartei und der faschistischen Ustaša-Bewegung zwischen 1929 und I94I, und beurteilt Mačeks Erbe und seinen Platz in der politischen Geschichte Kroatiens im 20. Jahrhundert.

\section{Vladko Maček et la défense paysanne croate dans le royaume de Yougoslavie}

Dans les années I936-4I, le Parti paysan croate, dirigé par Vladko Maček, fit fonctionner deux milices: la défense paysanne croate (HSZ) dans les campagnes, la défense civile croate dans les villes. La HSZ était chargée de protéger les paysans croates des attaques des Chetniks serbes, mais aussi des communistes, et constituait en elle-même un symptôme de l'anarchie régnant dans le royaume de Yougoslavie dans l'entre-deux-guerres. La HSZ participait aussi aux efforts de Maček pour constituer avec le mouvement fasciste Ustasa une organisation armée, derrière ce qu'on appelle le 'Velebit soulèvement' de 1932. 


\section{Vladko Maček und die Kroatische Bauernwehr im Königreich Jugoslawien}

In den Jahren I936-4I unterhielt die Kroatische Bauernpartei, geführt von Vladko Maček, zwei Militäreinheiten - die Kroatische Bauernwehr (HSZ) in den Dörfern und die Kroatische Bürgerwehr in den Städten. Die HSZ sollte die kroatischen Bauern vor den Attacken der serbischen Tschetniks ebenso wie vor den Kommunisten schützen. Sie war so selbst ein Symptom der Gesetzlosigkeit, die zwischen den Kriegen im jugoslawischen Königreich herrschte. Die HSZ war ausserdem Teil von Mačeks Bemühungen, sich gegenüber der faschistischen Ustaša, einer bewaffnete Organisation, die hinter dem sogenannten 'Velebit Aufstand' von I932 stand, zu behaupten.

\section{Vladko Maček, le Parti paysan croate et la guerre civile espagnole}

Durant l'été I936, la priorité de Vladko Maček était de reconstruire le Parti paysan croate après six ans où il avait été frappé d'illégalité sous la dictature du roi Alexander dans le royaume de Yougoslavie. Pourtant, la guerre civile espagnole (1936-9) allait avoir des effets de polarisation et de radicalisation sur la société croate. Les communistes, comme les adhérents au mouvement fasciste Ustasa, regardaient l'Espagne comme un modèle pour résoudre la 'question croate', au moment où les Croates étaient très frustrés par la passivité de Maček. Alors qu'une guerre de propagande faisait rage dans la presse des radicaux de droite comme de gauche, le Parti paysan croate tenta d'ignorer le conflit. L'incapacité de Maček à mesurer l'impact de la guerre d'Espagne sur la situation politique croate souligne ses faiblesses de leader dans des moments difficiles. Le Parti paysan croate rata l'occasion de tenir une position morale forte contre le fascisme durant le conflit espagnol, et la barrière posée par Maček à partir des années trente a permis aux mouvements idéologiques extrêmes en Croatie de tirer avantage des conditions nouvelles d'une Europe engloutie dans la guerre.

\section{Vladko Maček, die Kroatische Bauernpartei und der Spanische Bürgerkrieg}

Im Sommer I936 lagen Vladko Mačeks Prioritäten im Wiederaufbau der Kroatischen Bauernpartei, die unter der Diktatur König Alexanders im Königreich Jugoslawien sechs Jahre lang illegal gewesen war. Doch der Spanische Buergerkrieg sollte einen polarisierenden und radikalisierenden Effekt auf die kroatische Gesellschaft haben. Beide, Kommunisten und Unterstützer der faschistischen Ustaša Bewegung, sahen Spanien als ein Modell für die Lösung der 'Kroatischen Frage' und dies zu einer Zeit, als die Kroaten immer unzufriedener mit Mačeks Passivität wurden. Während der Propagandakrieg in der Presse der radikalen Linken und Rechten tobte, versuchte die kroatische Bauernpartei, den Konflikt zu ignorieren. Mačeks Unvermögen, die Auswirkungen des Krieges in Spanien auf die politische Situation in Kroatien zu realisieren, weist auf seine Schwächen als Führer in schwierigen Zeiten hin. Die Kroatische Bauernpartei versäumte die Gelegenheit, während des spanischen Konfliktes eine entschiedene moralische Haltung gegenüber dem Faschismus einzunehmen. Mačeks abwartende Haltung in den I93oern erlaubte es den extremeren ideologischen Bewegungen in Kroatien, Vorteile aus den sich rasant verändernden Bedingungen eines im Krieg befindlichen Europas zu ziehen. 